\title{
Nerve Growth Factor in Alzheimer's Disease: Increased Levels throughout the Brain Coupled with Declines in Nucleus Basalis
}

\author{
Samuel A. Scott,, Elliott J. Mufson, ${ }^{3}$ Jean A. Weingartner, ${ }^{1}$ Kenneth A. Skau, ${ }^{2}$ and Keith A. Crutcher ${ }^{1}$ \\ 'Department of Neurosurgery and ${ }^{2}$ College of Pharmacy, University of Cincinnati, Cincinnati, Ohio and ${ }^{3}$ Department \\ of Neurology, Rush Presbyterian St. Luke's Medical Center, Chicago, Illinois
}

\begin{abstract}
The current study analyzed NGF protein levels in the brains of patients with Alzheimer's disease (AD) as compared with aged neurologically normal individuals. An established two-site ELISA was used to measure NGF-like immunoreactivity in the hippocampus, superior temporal gyrus, superior frontal gyrus, inferior parietal lobule, frontal and occipital cortical poles, cerebelium, amygdala, putamen, and nucleus basalis of Meynert (nbM). ChAT activity was assayed in adjacent tissue samples. NGF levels were also evaluated in Parkinson's disease for comparison with both $A D$ and age-matched control cases.
\end{abstract}

Regardless of the brain bank (University of Cincinnati, Rush Presbyterian St. Luke's Medical Center in Chicago, or University of Alabama at Birmingham), NGF-like activity was at least moderately increased with $A D$ in virtually every brain region examined except for the $\mathrm{nbM}$, in which significant declines were observed. NGF levels were also increased when compared with age-matched Parkinson's cases (frontal cortex). NGF-like activity was not related to age at onset or disease duration in AD cases, nor did NGF levels correlate with age at death in the control or AD groups. Correlations between ChAT and NGF-like activity across brains varied considerably and were generally not significant.

The present findings indicate that $A D$ is characterized by a widespread increase in cortical and subcortical NGF. Although a correlation with ChAT activity was not observed in cortex, the AD-related decline in NGF found in nbM is consistent with the possibility of impaired retrograde transport of NGF to this region.

[Key words: NGF, neurotrophin, ELISA, Alzheimer's disease, basal forebrain, human, amygdala, hippocampus, cortex, cerebellum, ChAT, aging]

The neuropathology of Alzheimer's disease (AD) is being increasingly viewed as a global disruption of brain circuitry involving multiple transmitter systems. However, most of the pharmacological approaches to treating AD have centered around the

Received Feb. 16, 1995; revised May 12, 1995; accepted May 16, 1995.

This work was supported by Grants NS31410 (K.A.C.), AG05605 (S.A.S), $\wedge$ G10161 and $\wedge$ G09166 (E.J.M.). We graciously thank Chris Clendening for assistance with the ChAT assay, Genentech Inc. for recombinant human NGF, and Dr. William Mobley for NGF antisera. Thanks also to Drs. Powers and Guozhu at the University of Alahama at Birmingham for providing additional brain tissue.

Correspondence should be addressed to Samuel A. Scott, Ph.D., Program in Physical Therapy, Barry University, 11300 N.E. 2nd Avenue, Miami Shores, FL 33161

Copyright (C 1995 Society for Neuroscience 0270-6474/95/156213-09\$05.00/0 cholinergic synapse (e.g., AChE inhibitors). No single approach has been particularly successful, although this has not discouraged the development of alternative tactics aimed at stabilizing cholinergic basal forebrain projections in AD.

One such strategy is the use of NGF, a protein with growthand survival-promoting effects on central cholinergic neurons both in vitro and in vivo (reviewed in Scott and Crutcher, 1994). Notwithstanding potential side effects of NGF administration (Butcher and Woolf, 1989; Scott and Crutcher, 1994) and complications with respect to mode of delivery (Hefti and Schneider, 1989; Saffran, 1992), it has been suggested that exogenous NGF, if appropriately administered, will prevent degeneration of these neurons in $\mathrm{AD}$ in a manner similar to that observed in the lesioned animal (reviewed by Scott and Crutcher, 1994).

Given the original suggestion that certain human neurologic disorders may be caused by reductions in trophic support (Appcl, 1981), and spccifically by loss of NGF in Alzheimer's dis ease (Appel, 1981; Hefti, 1983; Hefti and Weiner, 1986; Phelps et al., 1989), an initial study was undertaken to determine whether brain NGF levels were altered in AD using a bioassay and a well-established immunoassay (Crutcher et al., 1993). Surprisingly, NGF-like activity was found to be increased with AD in both the frontal and occipital poles of the cortex (Crutcher et al., 1993). This result seemed consistent with the possibility of impaired retrograde transport of NGF to the cholinergic basal forebrain, particularly when considering the AD-related loss of NGF receptor-bearing neurons in this region (Hefti and Mash, 1989; Kordower et al., 1989b; Mufson et al., 1989a; Allen et al., 1990; Loy et al., 1990; Strada et al., 1992).

The present investigation was undertaken to further analyze NGF levels in human brain in order to deternine: (1) whether AD-related increases in NGF are restricted to areas receiving basal forebrain cholinergic input; (2) whether such increases also occur in Parkinson's disease, another age-related neurodegenerative disorder; and (3) whether correlations exist between target NGF levels and the amount of ChAT activity in the same tissue samples. We hypothesized that if NGF levels are elevated in response to removal of cholinergic input, as they are in rodent hippocampus following destruction of septal axons (Scott et al., 1994), then a negative correlation should exist between NGF and ChAT activity in the target tissue. Moreover, the levels of NGF should be decreased within the cholinergic basal forebrain in AD. We found the latter to be the case, although correlations between NGF and ChAT activity were not robust and varied widely across brain regions.

\section{Materials and Methods}

Subjects. Postmortem-derived tissue samples from 59 patients, including 30 from the University of Cincinnati (UC), 12 from the University of 
Table 1. Case demographics of tissue samples

\begin{tabular}{|c|c|c|c|c|c|c|c|c|}
\hline Tissue source & Group & $N$ & Gender & $\begin{array}{l}\text { Brain } \\
\text { wt }(\mathrm{gm})\end{array}$ & Age $(y r)$ & PMD (hr) ${ }^{n}$ & $\begin{array}{l}\text { Storage } \\
(\mathrm{mo})^{b}\end{array}$ & Brain regions \\
\hline \multirow{2}{*}{$\begin{array}{l}\text { University of } \\
\text { Cincinnati }\end{array}$} & Control & 13 & $7 \mathrm{M}, 6 \mathrm{~F}$ & $1217 \pm 47$ & $68 \pm 3.4$ & $12 \pm 1.7$ & $28 \pm 7.2$ & \multirow{2}{*}{$\begin{array}{l}\text { Hippocampus, amygdala, } \\
\text { putamen, cerebellum, various } \\
\text { cortical regions }\end{array}$} \\
\hline & $\mathrm{AD}$ & 17 & $7 \mathrm{M}, 10 \mathrm{~F}$ & $1149 \pm 43$ & $82 \pm 2.4$ & $12 \pm 1.8$ & $10 \pm 3.2^{d}$ & \\
\hline \multirow{2}{*}{$\begin{array}{l}\text { University of } \\
\text { Alabama at } \\
\text { Birmingham }\end{array}$} & Control & 6 & $5 \mathrm{M}, 1 \mathrm{~F}$ & $1328 \pm 20$ & $69 \pm 3.9$ & $7 \pm 1.1$ & $25 \pm 3.3$ & \multirow{2}{*}{$\begin{array}{l}\text { Hippocampus, superior temporal } \\
\text { gyrus }\end{array}$} \\
\hline & $\mathrm{AD}$ & 6 & $2 \mathrm{M}, 4 \mathrm{~F}$ & $1128 \pm 40^{c}$ & $68 \pm 3.7$ & $7 \pm 1.4$ & $36 \pm 1.1^{\prime}$ & \\
\hline \multirow[t]{3}{*}{ Rush Presbyterian } & Control & 6 & $3 \mathrm{M}, 3 \mathrm{~F}$ & $1243 \pm 64$ & $71 \pm 2.9$ & $11 \pm 2.3$ & $26 \pm 7.8$ & \multirow{3}{*}{$\begin{array}{l}\text { Nucleus basalis, superior frontal } \\
\text { gyrus, inferior parietal lobule }\end{array}$} \\
\hline & $\mathrm{AD}$ & 6 & $2 \mathrm{M}, 4 \mathrm{~F}$ & $983 \pm 57^{n}$ & $69 \pm 2.2$ & $5 \pm 0.8^{i}$ & $25 \pm 2.7$ & \\
\hline & $\mathrm{PD}^{g}$ & 5 & $3 \mathrm{M}, 2 \mathrm{~F}$ & $1331 \pm 58$ & $69 \pm 1.4$ & $6 \pm 1.3$ & $17 \pm 5.6$ & \\
\hline
\end{tabular}

"Postmortem delay (interval between death and freezing of tissue).

${ }^{b}$ Length of time tissue was stored frozen $\left(-80^{\circ} \mathrm{C}\right.$ or below).

" $P=0.0018$ vs control; all values are mean + SEM.

" $P=0.0172$ vs control.

* $P=0.0012$ vs control.

${ }^{f} P=0.0133$ vs control.

"Parkinson's disease.

" $P=0.0122$ vs control and 0.0022 vs PD

i $P=0.0394$ vs control.

Alabama at Birmingham (UAB), and 17 from Rush-Presbyterian-St. Luke (Rush), were used in this study. Subjects classified as AD were diagnosed clinically and neuropathologically (McKhann et al., 1984; Khachaturian, 1985). The age at which symptoms were first noted was documented for 11 of 17 UC patients, averaging $73 \pm 3.4$ years (SEM). This resulted in a mean illness duration of $6.9 \pm 0.9$ years (range 3 13 years). Pathologic evaluation of aged controls revealed no evidence of $\mathrm{AD}$ or other type of dementia. Subjects with Parkinson's disease, obtained through Rush, were diagnosed based on standard clinical and histological criteria (Mirra et al., 1993) and also displayed no clinical or pathological signs of $\mathrm{AD}$. Table 1 displays the case demographics for tissue used in this study.

Control subjects obtained through UC and Rush died from various causes including myocardial infarction, congestive heart failure, urinary tract infection, pneumonia, sepsis, peritonitis, bowel infarcts, and renal failure. In contrast, control subjects from UAB all dicd from accidents, and did not exhibit any neurologic disease process at the time of death. There was no clinical evidence of metastatic tumor, seizure, dementia, alcoholism, AIDS, or hepatitis in any control patient. Most of the AD cases in this study were brain-only autopsies, so it was often impossible to determine the direct cause of death (although pneumonia was a frequently documented terminal event). There was no gross or histological evidence of neoplasia, spongy state, hypoxia, infarct, hemorrhage, or other such abnormality in any tissue block used in this study.

Brain areas. Samples from eight regions of the left hemisphere were evaluated from UC brain donors: frontal pole (Brodmann area 10), superior temporal gyrus (area 22, anterior to Heschl's gyri), inferior parietal lobule (area 39), primary visual cortex (area 17), posterior basolateral amygdala (including the lateral, basal, and accessory basal nuclei), Ammon's horn and dentate gyrus of the mid-rostrocaudal hippocampal formation, mid-rostrocaudal putamen, and the posterior lobe of the cerebellum. Snap-frozen samples of the nucleus basalis of Meynert (nbM), obtained from Rush, included mainly the anteromedial and anterolateral subfields. Sections of hippocampus and superior temporal gyrus (same anatomical locations as above) were provided from UAB by Dr. Richard Powers. Blocks were taken from precisely the same area of every brain using gross anatomical landmarks. Samples were harvested during autopsy and stored immediately at $-80^{\circ} \mathrm{C}$ until processed. Table 1 lists the brain areas obtained from each tissue source.

On the day or two preceding the ELISA, two coronally adjacent tissue samples were cut from each block, weighed $(\sim 100 \mathrm{mg})$, and placed in vials that were again stored at $-80^{\circ} \mathrm{C}$ prior to use in the assays described below. Only gray matter was included in samples from the ncocortex.

Immunological assay. The ELISA was modified from an established protocol (Weskamp and Otten, 1987) as described previously in detail
(Saffran et al., 1989; Crutcher et al., 1993). Monoclonal antibodies raised against mouse NGF were kindly provided by Dr. William Mobley (UCSF). The polyclonal antiserum was raised in a goat by Hazelton Research Products, Inc. (Denver, PA) using purified mouse NGF according to an established protocol (Saffran et al., 1989). Tissue samples were dissected as described above and homogenized for 3 min at a 1:10 dilution in sample buffer containing $0.1 \%$ Tween $20,0.5 \%$ bovine serum albumin, $0.1 \mathrm{~mm}$ benzethonium chloride, $1 \mathrm{mg} / \mathrm{ml}$ aprotinin, and $0.1 \mathrm{~mm}$ phenylmethyl sulfonyl fluoride prepared in $10 \mathrm{~mm}$ phosphatebuffered saline. The amount of NGF-like activity in each supernatant was subsequently calculated relative to standard curves generated on the same plates (NUNC, Irvine Scientific, Santa Ana, CA) using known concentrations $(1.56,3.12,6.25,12.5,25,50$, and $100 \mathrm{pg} /$ well) of recombinant human NGF (provided by Genentech, Inc.). Optical densities were determined using orthophenylenediamine (Sigma, St. Louis MO) as chromagen and then converted to ng/gm of tissuc wct wcight.

Choline acetyltransferase (ChAT) assay. Samples of brain extract were reacted $\left(37^{\circ} \mathrm{C}\right)$ with $0.2 \mathrm{~mm}$ acetyl coenzyme $\mathrm{A}$ in the presence of $0.1 \mathrm{~mm}$ physostigmine salicylate, $2.0 \mathrm{~mm}$ EDTA, $8 \mathrm{~mm}$ choline iodide, and trace amounts of ${ }^{14} \mathrm{C}$-acetyl coenzyme A. After 6 min the reaction was terminated with $2.0 \mathrm{M}$ formic acid and the $\mathrm{ACh}$ was extracted into octanone containing $15 \mathrm{mg} / \mathrm{ml}$ tetraphenylooron. A sample of the organic layer was counted by liquid scintillation at approximately $80 \%$ efficiency. Choline acetyltransferase was expressed as nanomoles of ACh formed per hour per milligram of protein.

Statistical analyses. Groups of data were compared parametrically using unpaired or paired $t$ tests, or analysis of variance (ANOVA) where appropriate. Simple linear regression analyses were used to assess relationships between variables across subjects within a group.

\section{Results}

\section{Group demographics}

Control and AD subjects were age-matched except for the UC patient sample, in which AD subjects were significantly older than controls by an average of 14 years (Table 1). Postmortem interval, with group means ranging from 5 to $12 \mathrm{hr}$, did not differ between control and $\mathrm{AD}$ brains except regarding samples obtained from Rush, in which the interval was significantly shorter for $\Lambda \mathrm{D}$ versus control cases. The male-to-female ratio was sim. ilar between control and AD groups obtained from UC and from Rush, whereas an imbalance was noted for UAB samples (controls were mostly male and AD subjects were mostly female). The length of time the tissue was kept frozen prior to assay was 


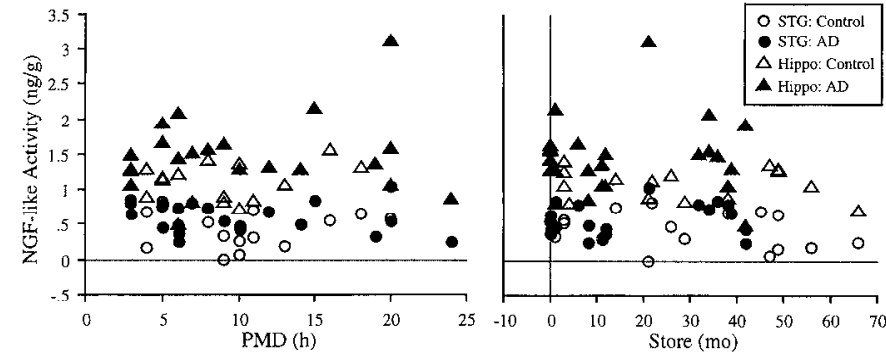

Figure 1. Relative stability of NGF-like activity in postmortem human brain tissue. NGF levels in the superior temporal gyrus (STG) and hippocampus (Hippo) did not correlate with the length of storage time (in the frozen state) or with postmortem delay $(P M D)$. The average correlation coefficient concerning PMD was 0.13 , with $P$ values ranging from 0.42 to $0.99(-18$ subjects per comparison). Regarding storage time, the average correlation coefficient was 0.18 with $P$ values ranging from 0.26 to 0.96 ( $\sim 20$ subjects per comparison). Correlations were nonsignificant whether based on samples from UC and UAB combined or from UC only.

significantly greater in control versus AD subjects obtained from UC, but significantly lower in control versus AD subjects obtained from UAB; no difference was observed in Rush samples (Table 1). Brain weight was significantly decreased with AD in $\mathrm{UAB}$ as well as in Rush cases (Table 1). All of these variables were assessed for a possible relationship with NGF protein levels, as described below.

\section{Stability of $N G F$}

There was no loss of NGF-like immunoreactivity associated with postmortem delay in either control or AD patient groups, based on hippocampal and cortical samples obtained 3-24 hr postmortem (Fig. 1). NGF-like immunoreactivity did not appear to be influenced by the time the tissue was stored frozen at $-80^{\circ} \mathrm{C}$, which ranged from several days to $\sim 70$ months (Fig. 1).

\section{NGF and gender}

To determine whether a relationship existed between gender and NGF-like immunoreactivity in postmortem tissue samples, hippocampal NGF levels in male and in female UC patients were compared. No effect of gender could be demonstrated in either the control $[t(1,9)=-0.7, P=0.5026]$ or $\mathrm{AD}$ group $[t(1,15)$ $=0.6, P=0.5562]$. Samples of other brain areas and from the remaining tissue sources were generally too small for statistical comparison.

\section{NGF and brain weight}

There was no detectable relationship between NGF-like immunoreactivity and brain weight based on regression analyses performed on hippocampal tissue samples within each UC patient group ( $P>0.34$ in all comparisons). However, the trend was toward a negative correlation in every comparison (i.e., the lower the brain weight, the greater the NGF-like immunoreactivity). No relationship could be found between NGF-like immunoreactivity and total protein levels (mg protein/gm wet weight), or between total protein levels and the presence of AD (data not shown).

\section{NGF-like immunoreactivity in human brain}

When averaged across all aged control patients, absolute levels of NGF-like immunoreactivity were highest in the hippocampal formation and $\mathrm{nbM}$ (both $\sim 1.1 \mathrm{ng} / \mathrm{gm}$, or $1100 \mathrm{pg} / \mathrm{gm}$ ) followed

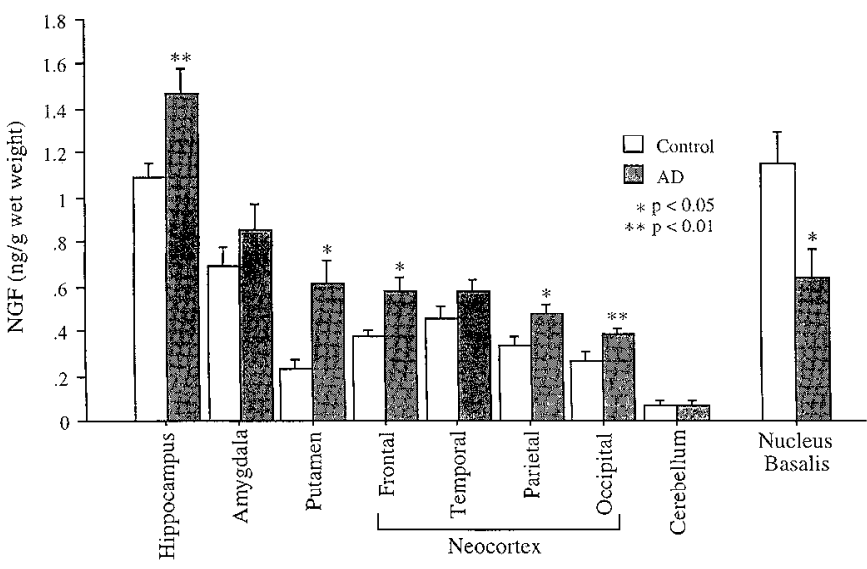

Figure 2. NGF-like immunoreactivity in Alzheimer's disease $(A D)$ across various regions of the human brain (see Table 1 for sample sizes). Increases in NGF-like activity relative to the control group are pronounced in areas not traditionally known to be affected in $\mathrm{AD}$, including the putamen as well as the frontal and occipital poles. In contrast to these changes, tissue samples from the nbM revealed a $50 \%$ AD-related decline in NGF levels (five control and six AD subjects).

by amygdala $(690 \mathrm{pg} / \mathrm{gm})$, temporal cortex $(450 \mathrm{pg} / \mathrm{gm})$, frontal cortex $(330 \mathrm{pg} / \mathrm{gm})$, parietal cortex $(330 \mathrm{pg} / \mathrm{gm})$, occipital cortex ( $270 \mathrm{pg} / \mathrm{gm})$, putamen $(230 \mathrm{pg} / \mathrm{gm})$, and cerebellum $(60 \mathrm{pg} / \mathrm{gm})$. Levels of NGF were also high in the caudate nucleus, medial thalamus, and choroid plexus (data not shown). These data closely parallel the distribution of NGF-like immunoreactivity in rat and monkey brain (reviewed by Scott and Crutcher, 1994).

\section{NGF levels in Alzheimer's disease}

NGF levels were subsequently assessed as a function of $\mathrm{AD}$ based on our UC patient population. In every brain region examined, absolute levels of NGF were higher in AD versus control patients (Fig. 2). The increases were significant at the $\alpha=$ 0.05 level in five of the eight comparisons (hippocampus, putamen, inferior parietal lobule, and the frontal and occipital poles). It should be noted that a different group of patients was investigated in our previous report (Crutcher et al., 1993), in which AD-related increases in the frontal and occipital poles were also found.

Tissues were subsequently acquired from UAB in order to determine whether the AD-related increases in hippocampus and superior temporal gyrus would be present in tissue from another source. Based on six AD and six age-matched control subjects, we confirmed a significant $\mathrm{AD}$-related increase in NGF-like activity. This increase was bilateral (see Fig. $5 B$ ). Additional samples of the superior frontal gyrus, obtained from six AD and three age-matched controls through Rush, also revealed a significant $\mathrm{AD}$-related increase in $\mathrm{NGF}$-like activity $[t(1,7)=$ -5.04, $P=0.0015$ ] (see Fig. 6). A further analysis compared NGF levels in the inferior parietal lobule of two controls and five AD patients, also from Rush. The AD-related increase hased on these samples was $36 \%$, as compared with $48 \%$ based on UC samples (Fig. 2).

In contrast, tissue samples of the nucleus basalis of Meynert ( $\mathrm{nbM}$ ), harvested from the same Rush cases (see above) as well as two additional controls, revealed a 50\% AD-related decline in NGF ( $P=0.0255$; Fig. 2). AD-related increases in neocortical NGF-like activity coupled with declines in $\mathrm{nbM}$ were thus present in the same brains. 


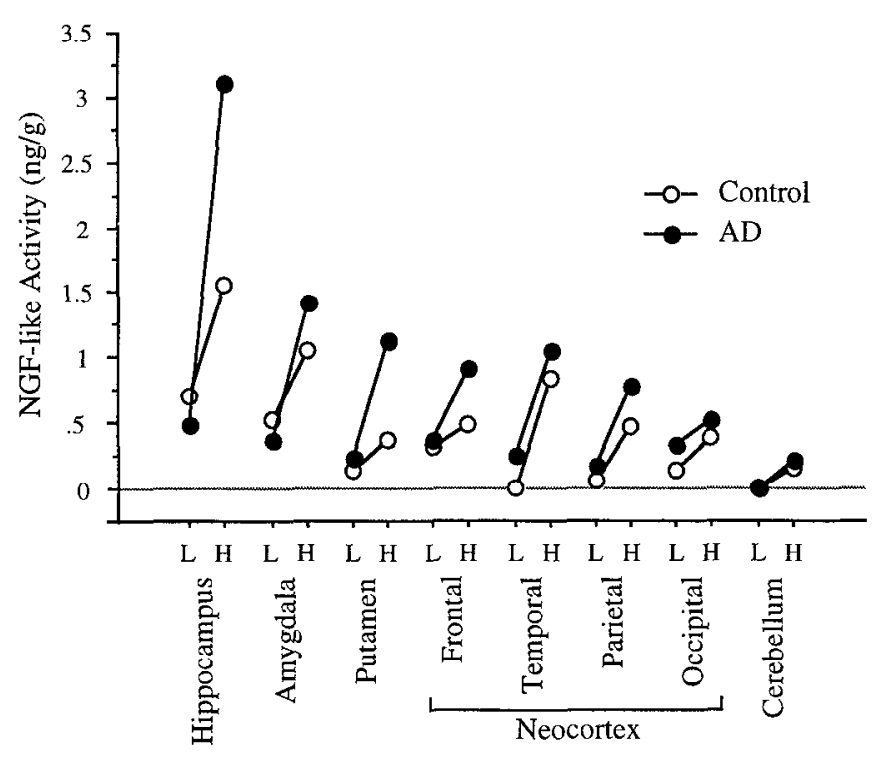

Figure 3. Lowest $(L)$ and highest $(H)$ subject levels of NGF-like immunoreactivity in each patient group. Each dot represents one subject. AD subjects always manifested the highest individual values whereas the control group did not always contain the lowest values. By paired $t$ test, only the highest individual values were significantly greater in $\mathrm{AD}$ versus control cases $[t(1,7)=-2.79, P=0.0268]$. There was no significant difference regarding the lowest values $(P=0.4604)$.

\section{NGF-like activity and patient age}

In the superior temporal gyrus, there was a strong tendency towards an age-related decline in NGF-like activity in both the control $[r=-0.55 ; F(1,14)=6.19, P=0.0261]$ and $\mathrm{AD}$ groups $[r=-0.34 ; F(1,21)=2.78, P=0.1092]$. Correlations between age and NGF-like activity were not apparent in other subregions ( $P$ values $>0.28)$.

\section{Age at onset and duration of illness}

NGF-like immunoreactivity was not correlated with age at onset of dementia $(-0.33 \leq r \leq 0.06)$ nor with estimated duration of dementia $(0.12 \leq r \leq 0.28)$ based on $11 \mathrm{AD}$ patients obtained from UC (temporal cortex, parietal cortex, and hippocampus analyzed separately). Nevertheless, a wide range of NGF-like activity was found in both groups, irrespective of brain region. This was underscored by the fact that the highest levels within each region were always from $\mathrm{AD}$ patients, whereas the lowest levels were also occasionally from AD patients (Fig. 3).

Despite this range, levels of NGF revealed a consistent positive correlation between various regions of the same brain (Fig. 4). For example, patients with high levels of NGF-like activity in the hippocampus also tended to have high levels in the neocortex and/or amygdala.

\section{NGF levels and ChAT activity}

ChAT levels in UAB tissue samples were bilaterally declined as a function of $\Lambda \mathrm{D}$ in both hippocampus and superior temporal gyrus (Fig. 5A). Conversely, AD-related increases in NGF were found in virtually the same tissue samples (Fig. 5B), suggesting that NGF levels may be inversely correlated with ChAT activity. When ChAT levels were analyzed with respect to $\mathrm{AD}$ in UC samples, significant declines with $\mathrm{AD}$ were present only in hippocampus $[t(1,23)=2.12, P=0.0449]$ and amygdala $[t(1,7)$
$=3.39, P=0.0483]$. The average AD-related decline in ChAT activity was $20 \%$ among regions listed in Figure 2.

Considering all brain regions, ChAT levels did not correlate with NGF-like activity in a robust or consistent manner (Table 2). However, the strongest trend was toward a negative correlation in hippocampus (Table 2). ChAT activity did not correlate with postmortem delay in any comparison (data not shown).

\section{NGF levels in Parkinson's disease}

NGF-like activity was also studied in patients with Parkinson's disease (PD), obtained from Rush, for comparison with agematched control and AD subjects (Fig. 6). Relative to the control group, NGF-like activity was signiticantly increased only in AD (Fig. 6). NGF levels were also significantly higher in AD versus $\mathrm{PD}$ patients $[t(1,9)=3.36, P=0.0084]$.

\section{Discussion}

Methodological considerations when measuring NGF-like immunoreactivity

In a previous assessment of NGF-like activity in human brain (Crutcher et al., 1993), no cross-reactivity with the recombinant human proteins BDNF or NT-3 could be detected using this twosite ELISA. The standard curves are reliable using either mouse or recombinant human NGF (Crutcher et al., 1993). In fact, levels of human NGF-like immunoreactivity detected with this assay parallel the degree of NGF-like biological activity in the same tissue samples (Crutcher et al., 1993) using an established bioassay (Scott et al., 1994). Group differences in NGF-like activity do not depend upon whether values are corrected for recovery (a method of estimating the extent to which endogenous NGT may be degraded), nor do they depend on how the activity is expressed (ng/gm tissue wet weight or per milligram of protein; Crutcher et al., 1993). Furthermore, the absolute level of NGF-like activity detected in the current assay is similar to that detected by others in human (Allen et al., 1991a) and rat brain (Scott et al., 1994). Protease inhibitors were included in the homogenizing solution, further ruling out any differential effect of endogenous protease inhibitors on NGF-like immunoreactivity.

Postmortem delay (PMD) did not affect NGF-like activity within the ranges studied. This confirms a previous finding of no relationship between PMD and NGF-like immunoreactivity in human brain tissue within this time range (Crutcher et al., 1993). The highest NGF level reported in the current study (3.1 ng/gm wet weight) was from an AD patient with a 20 hr PMD. In fact, NGF-like immunoreactivity was readily detectable in samples of human parahippocampal gyrus left unfixed and unfrozen at $4^{\circ} \mathrm{C}$ for at least $8 \mathrm{~d}$ postmortem (data not shown). Together, these findings suggest that moderate delays in tissue freezing have little or no effect on NGF-like immunoreactivity as determined by ELISA. We were also unable to demonstrate a relationship between NGF-like activity and tissue storage time. This is supported by the finding of consistent AD-related increases in NGF (see below) regardless of whether AD samples were stored longer or shorter than control samples. It is presently unknown whether longer storage times (i.e., $>5-6$ yr) affect NGF-like activity in human brain tissue samples.

NGF in Alzheimer's disease: increased activity in multiple brain areas

NGF-like activity was at least moderately increased with AD in every brain region examined with the exception of nbM. 'These data demonstrate that the observed AD-related increases in NGF 

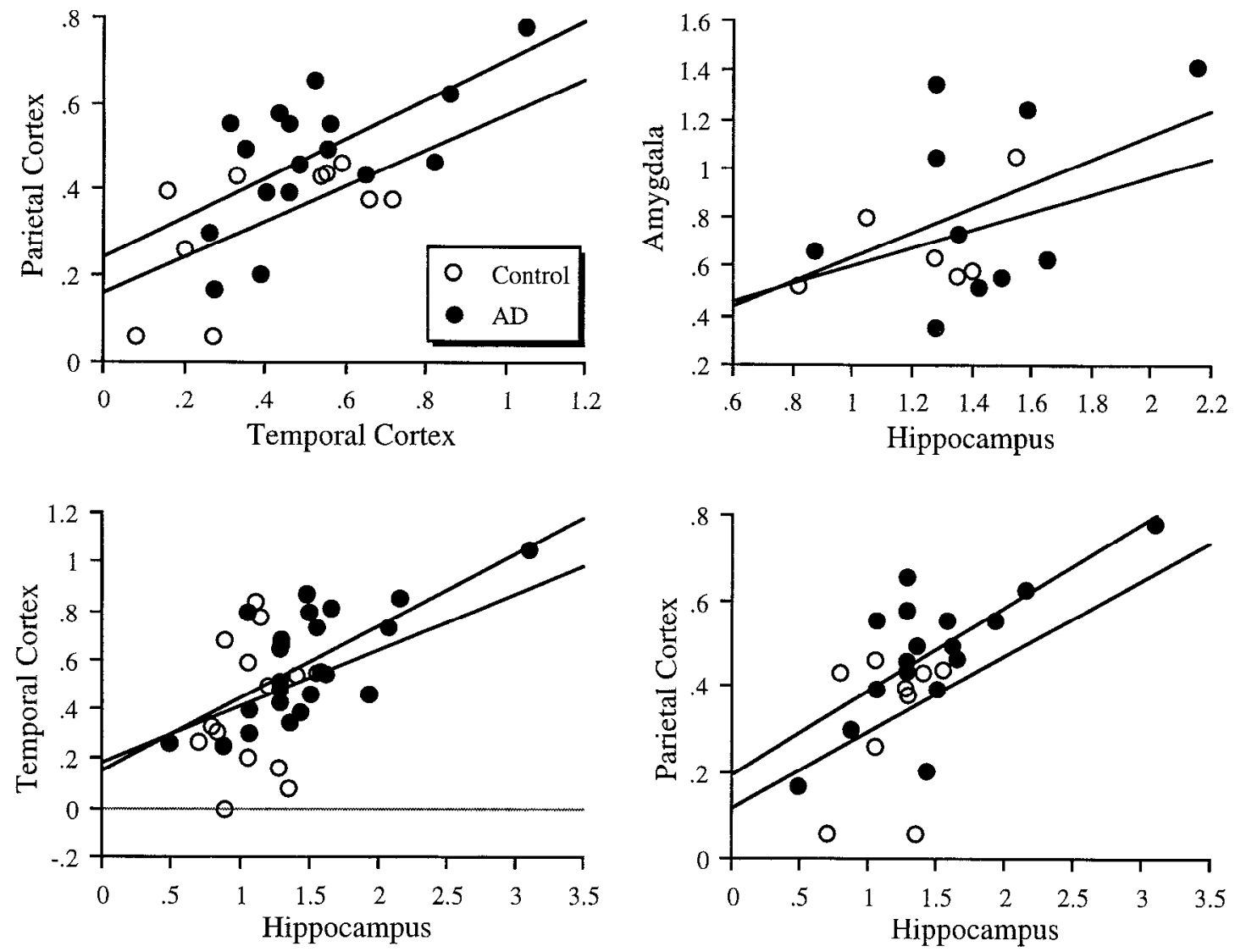

Figure 4. Scatterplots showing the relationship between NGF levels (ng/gm) within different regions of the same brain (each dot represents one brain). The average correlation coefficient for control groups was 0.41 compared with 0.62 for AD subjects (three of the four AD correlations were significant at the $\alpha=0.05$ level). These data suggest that AD-related increases in NGF represent a widespread response to a primary underlying disease process.

are not unique to a particular tissue source, nor to the frontal and occipital poles of the neocortex. The AD-related increases in NGF were not confounded by group differences in subject age, as indicated previously by covariance analyses (Crutcher et al., 1993) in which a correlation between patient age and NGF is assumed. AD-related increases in NGF were also observed when age-matched control subjects were utilized. In addition, levels of NGF in the frontal cortex of AD patients were high when compared with age-matched PD cases, suggesting that not all age-related neurodegenerative conditions are characterized by increased NGF. Assessment of additional subjects, brain areas, and neurological disorders will be necessary before drawing firm conclusions regarding the latter possibility.

The current findings along with a previous report (Crutcher et al., 1993) are in general agreement with Allen et al., (1991) whose data suggested moderate, though statistically insignificant, AD-related increases in NGF-like immunoreactivity in several cortical regions. Murase et al. (1993) described no effect of AD on NGF-like immunoreactivity in hippocampus and parietal cortex although the $\Lambda \mathrm{D}$ means were higher in both comparisons (see Scott and Crutcher, 1994). In contrast, a recent abstract by Hamill et al., (1993a) described a significant AD-related reduction in NGF-like immunoreactivity within the superior temporal gyrus. Several methodological factors (e.g., differences in ELISA protocol or tissue storage time) could account for this discrepancy. The fact that all AD patients in that study were in a "vegetative state" prior to death (MD Lindner, personal communication) may also be relevant. In order to consider possible differences in patient populations as a function of tissue source, we analyzed samples obtained from three different brain banks. The fact that AD-related increases in NGF were observed regardless of the source suggests that increased cortical NGF-like activity is a general characteristic of AD.

\section{Increased NGF in response to denervation}

Destruction of the septohippocampal pathway in adult rodents leads to a significant increase in hippocampal NGF-like activity (Collins and Crutcher, 1985; Gasser et al., 1986; Korsching et al., 1986; Weskamp et al., 1986a,b; Larkfors et al., 1987; Collins and Crutcher, 1989; Lindefors et al., 1992; Scott et al., 1994). However, hippocampal NGF mRNA levels show no change following septal denervation in adult animals (Goedert et al., 1986; Korsching et al., 1986; Whittemore et al., 1986) and cortical levels are stable following nbM lesioning (Goedert et al., 1986). These data provide a model in which NGF protein levels passively accumulate within the innervation territories of damaged cholinergic basal forebrain neurons. Considering the loss of NGF-consumer basal forebrain neurons in AD (Hefti and Mash, 1989; Kordower et al., 1989b; Mufson et al., 1989a; Loy et al., 1990; Strada et al., 1992; Mufson et al., 1995), we hypothesized that NGF levels would be increased within the target tissues of these neurons. 


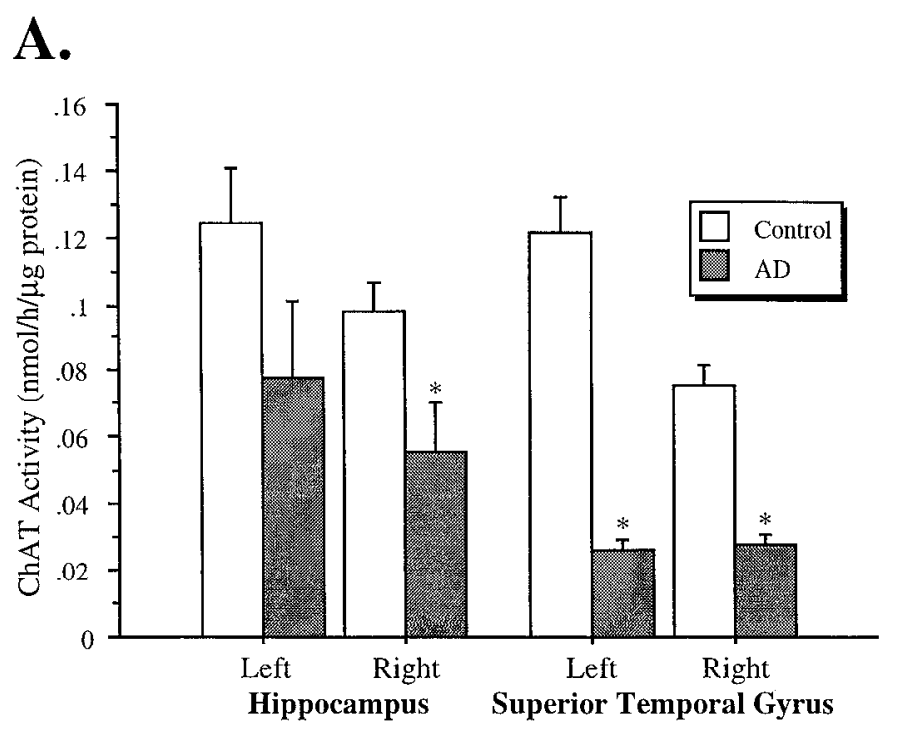

$* P<0.05$

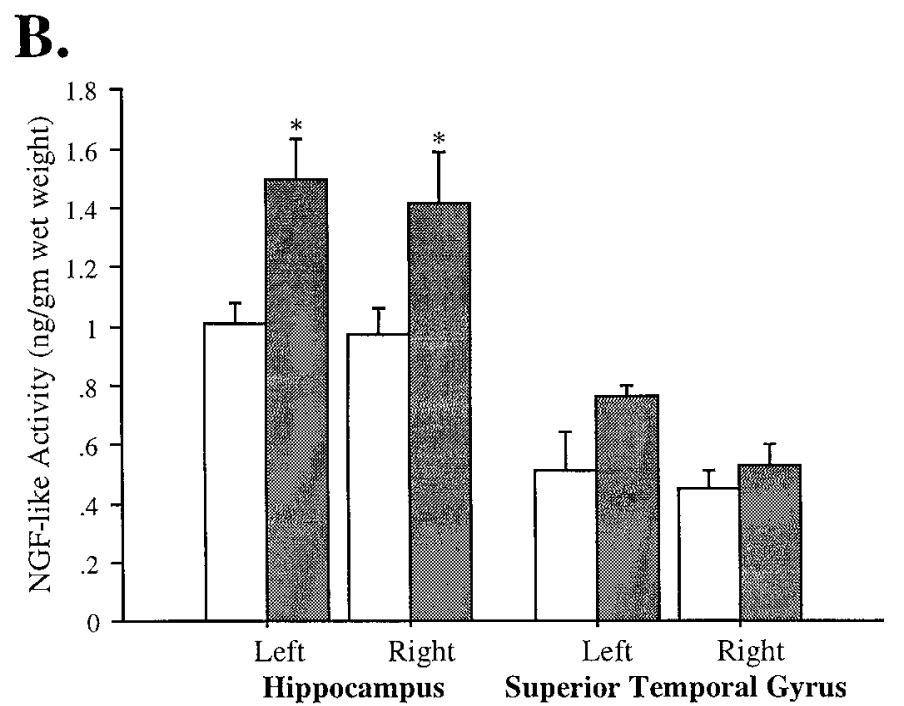

Figure 5. ChAT activity and NGF-like immunoreactivity (mean \pm SEM) measured in the same tissue samples from UAB patients with and without AD. AD was accompanied by a bilateral decline in ChAT activity $(A)$ with the greatest reduction occurring in the superior temporal gyrus $(P<0.001)$. Conversely, NGF-like activity was significantly increased $[B ; F(1,10)=9.27, P=0.0124]$. NGF levels were significantly higher in hippocampus versus superior temporal gyrus $[F(1,11)=79.21, P=0.0001]$. In addition, there was a nonsignificant tendency for greater NGF levels to occur in the left hemisphere $[F(1,11)$ $=3.08, P=0.1070]$.

However, NGF levels were also elevated in the putamen, a region that does not receive nbM input. The frontal and occipital cortical poles receive only modest innervation from the basal forebrain (Mesulam et al., 1983) but show significant increases in NGF-like activity. Combined with the tendency for multiple regions to display increased NGF in a given AD patient (Fig. 4), these data indicate a widespread increase in NGF irrespective of nbM input.

It has been known for some time that NGF binds to a low affinity rcceptor (p75 NGFR; Bothwell, 1991). Whilc p75 NGFR likely plays a role in the activity of several neurotrophins, signal
Table 2. Correlation between NGF levels and ChAT activity

\begin{tabular}{lllcl} 
& & \multicolumn{3}{c}{ Sample } \\
Brain rcgion & Group & $r$ & $(n)$ & $P$ valuc \\
\hline Hippocampus (UAB) & C & -0.85 & 6 & $0.034^{*}$ \\
& AD & -0.74 & 6 & 0.094 \\
Hippocampus & C & -0.48 & 10 & 0.132 \\
& AD & +0.09 & 14 & 0.765 \\
Amygdala & C & -0.77 & 4 & 0.228 \\
Frontal pole & AD & -0.12 & 5 & 0.849 \\
Sup temp. gyrus (UAB) & C & +0.57 & 6 & 0.238 \\
Sup. temp. gyrus & AD & +0.56 & 6 & 0.243 \\
Inf. parietal lobule & AD & -0.57 & 6 & 0.240 \\
Primary visual cortex & C & +0.19 & 6 & 0.725 \\
& AD & +0.47 & 10 & 0.167 \\
& C & +0.35 & 13 & 0.297 \\
& AD & +0.06 & 13 & 0.322 \\
& AD & +0.13 & 6 & 0.839 \\
& -0.38 & 6 & 0.464
\end{tabular}

Data show relationship between NGF-like activity and ChAT levels in left hemispheric tissue samples obtained either from UC or UAB (UC if not specified). Samples from both sources suggested an inverse relationship between NGF and ChAT activity in hippocampus. Samples from the right hemisphere of UAB patients also manifested the same trend $(r=0.46$ and 0.51 in control and $\mathrm{AD}$ groups, respectively; data not shown). C, Control subjects; AD, Alzheimer subjects; *, $P<0.05$.

transduction for NGF specifically requires interaction with a high affinity tyrosine kinase receptor, referred to as trkA (Bothwell, 1991). Recent immunohistochemical (Steininger et al., 1993; Sobreviela et al., 1994) and in situ hybridization experiments (Gibbs and Pfaff, 1994; Holtzmann et al., 1995) reveal a widespread distribution of trkA-containing neurons throughout the brain including, for example, the cholinergic perikarya of the putamen. Abnormalities in the utilization, internalization, or transport of NGF by this region as well as others could thus play

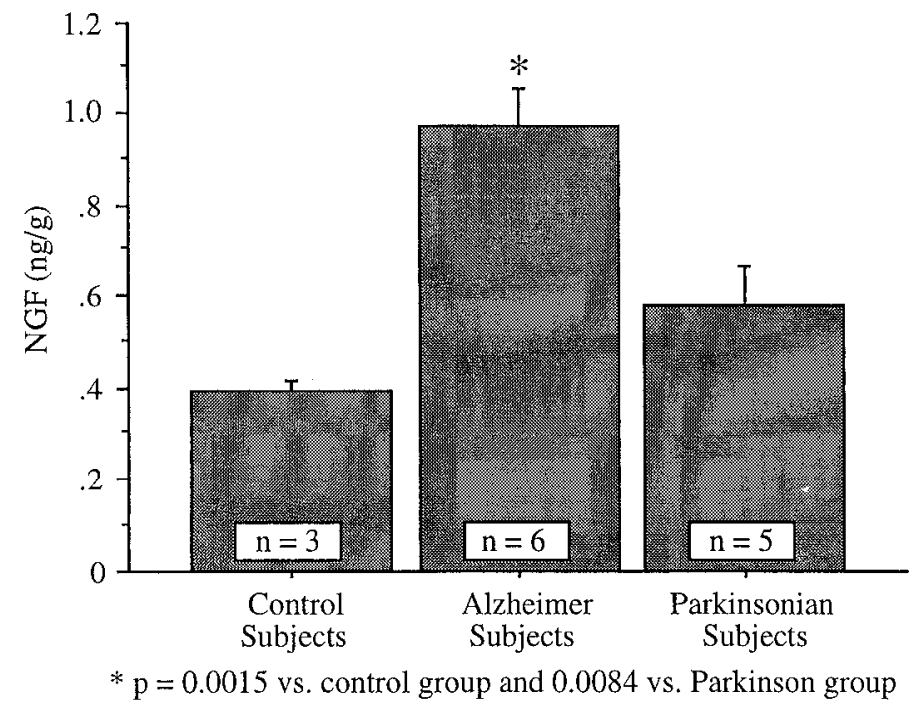

Figure 6. NGF-like activity in the superior frontal gyrus (mcan \pm SEM). Increased levels were observed in superior frontal gyrus from Alzheimer's but not Parkinson's patients when compared with agematched control tissue. All samples were obtained from Rush Presbyterian (see text). 
a role in the widespread increase in NGF-like activity in patients with $\mathrm{AD}$.

\section{Loss of NGF in basal forebrain}

If AD-related increases in cortical NGF result from impaired retrograde transport to cholinergic basal forebrain neurons (Mufson et al., 1994; Scott and Crutcher, 1994; Sobreviela et al., 1994), one would predict a substantial loss of NGF in nbM. In the present study, the AD-related decline in NGF within nbM was calculated at $50 \%$. However, this could reflect either loss of NGF-responsive nbM neurons, impairment in the retrograde transport of NGF, or both. Recent data (Mufson et al., 1995) show that in normal aged individuals, virtually all p75 NGFRcontaining nbM neurons are also immunoreactive for NGF. In contrast, in $\mathrm{AD}$ there is a marked dissociation, with many $\mathrm{p} 75$ NGFR-immunoreactive neurons containing little or no NGF-like immunoreactivity. This finding provides indirect support for impaired retrograde transport which may, in part, explain the overall reduction of NGF in this brain structure in $\mathrm{AD}$.

\section{NGF and ChAT activity}

It was further postulated that ChAT levels would correlate inversely with NGF-like activity. The rationale behind this prediction was that AD-related loss of cholinergic fibers should result in reduced ChAT activity, along with increased levels of NGF (since the NGF cannot be retrogradely transported). Therefore, the greater the loss in ChAT activity, the greater the increase in NGF. The current results generally failed to support this hypothesis (Table 2). In a previous study of NGF levels in young and old rats (Hellweg et al., 1990), NGF and ChAT also did not correlate in any brain region when performed across rats in each age group. However, the absence of a linear correlation does not rule out the possibility of a more complex relationship. A negative linear correlation would suggest that NGF levels continue to accumulate as $\mathrm{AD}$-related cholinergic denervation of the cortex proceeds. It is possible that the NGF protein is also being removed or broken down during this hypothetical process. Alternatively, levels of cortical NGF may simply be unrelated to the degree of nbM cholinergic input. The fact that relatively small sample sizes were used (Table 2) should also be taken into account.

Considering AD patients from UC, most of whom were lateonset cases, ChAT activity was significantly declined only in hippocampus and amygdala. In contrast, early-onset $\mathrm{AD}$ patients (from UAB) manifested dramatic losses in ChAT activity in the superior temporal gyrus. These observations agree with a previous study (Bird et al., 1983) in which early-onset AD patients showed widespread declines in ChAT activity, whereas declines in late onset patients were present only in hippocampus. Nevertheless, both groups in the present study (AD patients from $\mathrm{UC}$ as well as from UAB) manifested increased levels of hippocampal NGF-like activity relative to controls.

\section{Alternative rnecharisms for increased NGF-like activity in $A D$}

It is possible that NGF may be actively produced as a consequence of AD. Hippocampal NGF protein and/or mRNA levels in rodents can be upregulated by a variety of means, including deafferentation, electrical stimulation, and treatment with neurotoxins (Scott and Crutcher, 1994). Although most available evidence indicates that brain NGF is synthesized by neurons, abundant evidence exists for NGF synthesis and secretion by glial cells in culture. The substantial gliosis observed in AD is consistent with the possibility that glial synthesis contributes to increased NGF-like activity.

Many lines of evidence suggest that the immune system may play a role in NGF production, including in AD (Scott and Crutcher, 1994). Several other immune disorders in humans are characterized by increased levels of NGF (Dicou et al., 1993). These data collectively suggest that supranormal NGF levels may constitute a symptom in a host of diseases involving altered immune responses.

\section{The rationale for treating $A D$ with $N G F$}

Much experimental evidence has recently been generated in favor of treating $\mathrm{AD}$ with exogenous NGF. This evidence shows that NGF stimulates central cholinergic neurons under a variety of circumstances (Hefti et al., 1989; Scott and Crutcher, 1994), which takes on clinical significance under the premise that degeneration of cholinergic basal forebrain neurons lies at the heart of $\mathrm{AD}$ symptomatology. Most of these neurons express p75 NGFR (Hefti et al., 1986; Kordower et al., 1988; Batchelor et al., 1989; Hefti and Mash, 1989; Kordower et al., 1989b; Mufson et al., 1989b; Allen et al., 1990). The specific retrograde transport of NGF by these neurons is well established (Scott and Crutcher, 1994). These findings are consistent with the suggestion that NGF be used to treat $\mathrm{AD}$ and, in fact, at least one $\mathrm{AD}$ patient has already received intracerebroventricular NGF infusion, with mixed results (Olson et al., 1992).

However, no published study has shown that the $\mathrm{AD}$ brain contains less NGF than normal, either at the protein (Allen et al., 1991a; Crutcher et al., 1993; Murase et al., 1993; the current study) or mRNA level (Goedert et al., 1986; Ernfors et al., 1990; Phillips et al., 1991; Jette et al., 1994). ChAT and p75 NGFR neuronal staining remain colocalized in basal forebrain neurons in $\mathrm{AD}$ (Kordower et al., 1989b) and p75 NGFR binding characteristics of these perikarya appear unchanged (Allen et al., 1991b; Strada et al., 1992). It is even unclear whether nbM levels of p75 NGFR protein or its mRNA are altered overall in AD (Goedert et al., 1989; Higgins and Mufson, 1989) given the upregulation that seems to occur at the cellular level (Kordower et al., 1989; Ernfors et al., 1990; Mufson and Kordower, 1992). Combined with evidence for stimulation of p75 NGFR synthesis by NGF (Gage et al., 1989; Higgins et al., 1989; Miller et al., 1994; Gibbs and Pfaff, 1994), these data strongly suggest that NGF protein is abundantly available in $\mathrm{AD}$ brain. The rationale for providing additional NGF to AD patients must also consider the possible adverse consequences of NGF delivery within the CNS (Butcher and Woolf, 1989; Crutcher et al., 1993; Scott and Crutcher, 1994).

The finding of an AD-related increase in NGF does not necessarily argue against using exogenous NGF to treat $\mathrm{AD}$, since the observed increases are relatively small and may occur secondary to another pathological process. Substantially higher dos es of exogenous NGF, similar to those employed in animal models, might still be expected to benefit a neuronal system that is both NGF-sensitive and selectively vulnerable in AD. Either way, the present findings support a model of impaired retrograde transport of target-derived NGF to basal forebrain cholinergic neurons in AD (Mufson et al., 1994, 1995; Scott and Crutcher, 1994; Sobreviela et al., 1994). This hypothesis should be taken into consideration in future developmental strategies aimed at treating the disorder. 


\section{References}

Allen SJ, Dawbarn D, MacGowan SH, Wilcock GK, Treanor JJS, Moss TH (1990) A quantitative morphometric analysis of basal forebrain neurons expressing $\beta-\mathrm{NGF}$ receptors in normal and Alzheimer's disease brains. Dementia 1:125-137.

Allen SJ, MacGowan SH, Treanor JJS, Feeney R, Wilcock GK, Dawbarn D (1991a) Normal $\beta-N G F$ content in Alzheimer's disease cerebral cortex and hippocampus. Neurosci Lett 131:135-139.

Allen SJ, Treanor JJS, MacGowan SH, Wilcock GK, Dawbarn D (1991b) Distribution and characterization of $\beta$-nerve growth factor receptors in Alzheimer's disease. In: Growth factors and Alzheimer's disease (Hefti F, Brachet P, Will B, Christen Y, eds), pp 81-97. Berlin: Springer.

Appel SH (1981) A unifying hypothesis for the cause of amyotrophic lateral sclerosis, Parkinsonism, and Alzheimer disease. Ann Neurol 10:499-505.

Batchelor PL, Armstrong DM, Blaker SN, Gage FH (1989) Nerve growth factor receptor and choline acetyltransferase colocalisation in neurons within the rat forebrain: response to fimbria-fornix transection. J Comp Neurol 284:187-204.

Bird TD, Stranahan S, Sumi SM, Raskind M (1983) Alzheimer's disease: choline acetyltransferase activity in brain tissue from clinical and pathological subgroups. Ann Neurol 14:284-293.

Bothwell M (1991) Keeping track of neurotrophin receptors. Cell 65: 915-918.

Butcher LL, Woolf NJ (1989) Neurotrophic agents may exacerbate the pathologic cascade of Alzheimer's disease. Neurobiol Aging 10:555570.

Collins F, Crutcher KA (1985) Neurotrophic activity in the adult rat hippocampal formation: regional distribution and increase after septal lesion. J Neurosci 5:2809-2814.

Collins F, Crutcher KA (1989) Sustained elevation in hippocampal NGF-like biological activity following medial septal lesions in the rat. Brain Res 490:355-360.

Crutcher KA, Weingartner J (1991) Hippocampal NGF levels are not reduced in the aged Fischer 344 rat. Neurobiol Aging 12:449-454.

Crutcher KA, Scott SA, Liang S, Everson WV, Weingartner J (1993) Detection of NGF-like activity in human brain tissue: increased levels in Alzheimer's disease. J Neurosci 13:2540-2550.

Dicou E, Hurez D, Nerrière V (1993) Natural autoantibodies against the nerve growth factor in autoimmune diseases. J Neuroimmunol 47:159-168.

Ernfors P, Lindefors N, Chan-Palay V, Persson H (1990) Cholinergic neurons of the nucleus basalis express elevated levels of nerve growth factor receptor mRNA in senile dementia of the Alzheiner type. Dementia 28:138-145.

Gage FH, Batchelor PE, Chen KS, Chin D, Higgins GA, Koh S, Deputy S, Kosenberg MB, Hischer W, Björklund A (1989) NGF receptor reexpression and NGF mediated cholinergic neuronal hypertrophy in the damaged adult neostriatum. Neuron 2:1177-1185.

Gasser UE, Weskamp G, Otten U, Dravid AR (1986) Time course of the elevation of nerve growth factor (NGF) content in the hippocampus and septum following lesions of the septohippocampal pathway in rats. Brain Res 376:351-356.

Gibbs RB, Pfaff DW (1994) In situ hybridization detection of trkA mRN $\Lambda$ in brain: distribution, colocalization with p75 NGFR and upregulation by nerve growth factor. J Comp Neurol 341:324-339.

Goedert M, Fine A, Hunt SP, Ullrich A (1986) Nerve growth factor InRNA in peripheral and central rat tissues and in the human central nervous system: lesion effects in the rat brain and levels in Alzheimer's disease. Mol Brain Res 1:85-92.

Goedert M, Fine A, Dawbarn D, Wilcock GK, Chao MV (1989) Nerve growth factor receptor mRNA distribution in human brain: normal levels in basal forebrain in Alzheimer's disease. Mol Brain Res 5:1-7.

Hamill RW, Lindner MD, Loy R (1993a) Decline in levels of NGF protein and $\mathrm{p} 75$ receptor in Alzheimer's diseased cortex. Soc Neurosci Abstr 19:191.

Hefti F (1983) Is Alzheimer's disease caused by lack of nerve growth factor? Ann Neurol 13:109-110.

Hefti F, Mash DC (1989) Localization of nerve growth factor receptors in the normal human brain and in Alzheimer's disease. Neurobiol Aging 10:75-87.

Hefti F, Schneider LS (1989) Rationale for the planned clinical trials with nerve growth factor in Alzheimer's disease. Psychiatr Dev 4:297-315.
Hefti F, Weiner WJ (1986) Nerve growth factor and Alzheimer's disease. Ann Neurol 20:275-281.

Hefti F, Hartikka J, Salvatierra A, Weiner WJ, Mash DC (1986) Localization of nerve growth factor receptors in cholinergic neurons of the human basal forebrain. Neurosci Lett 69:37-41.

Hefti F, Hartikka J, Knusel B (1989) Function of neurotrophic factors in the adult and aging brain and their possible use in the treatment of neurodegenerative diseases. Neurobiol Aging 10:515-533.

Hellweg R, Fischer W, Hock C, Gage FH, Björkiund A, Thoenen H (1990) Nerve growth factor levels and choline acetyltransferase activity in the brain of aged rats with spatial memory impairments. Brain Res 537:123-130.

Higgins GA, Mufson EJ (1989) NGF receptor gene expression is decreased in the nucleus basalis in Alzheimer's disease. Exp Neurol 106:222-236.

Higgins GA, Koh S, Chen KS, Gage FH (1989) NGF induction of NGF receptor gene expression and cholinergic neuronal hypertrophy within the basal forebrain of the adult rat. Neuron 3:247-256.

Holtzman DM, Kilbridge J, Li Y, Cunningham ET Jr, Lenn NJ, Clary DO, Reichardt LF, Mobley WC (1995) TrkA expression in the CNS: evidence for the existence of several novel NGF-responsive CNS neurons. J Neurosci 15:1567-1576.

Jette N, Cole MS, Fahnestock M (1991) NGF mRNA is not decreased in frontal cortex from Alzheimer's disease patients. Mol Brain Res 25:242-250.

Khachaturian ZS (1985) Diagnosis of Alzheimer's disease. Arch Neurol 42:1097-1105.

Kordower JH, Bartus RT, Bothwell M, Schatteman G, Gash DM (1988) Nerve growth factor receptor immunoreactivity in the nonhuman primate (cebus appela): distribution, morphology, and colocalization with cholinergic enzymes. J Comp Neurol 277:465-486.

Kordower JH, Gash DM, Bothwell M, Hersh L, Mufson EJ (1989) Nerve growth factor receptor and choline acetyltransferase remain colocalized in the nucleus basalis (CH4) of Alzheimer's patients. Neurobiol Aging 10:67-74.

Korsching S, Heumann R, Thoenen H, Hefti F (1986) Cholinergic denervation of the rat hippocampus by fimbrial transection leads to a transient accumulation of nerve growth factor (NGF) without a change in mRNA NGF content. Neurosci Lett 66:175-180.

Larkfors L, Stromberg I, Ebendal T, Olson L (1987) Nerve growth factor protein level increases in the adult rat hippocampus after a specific cholinergic lesion. J Neurosci Res 18:525-531.

Larkfors L, Ebendal T, Whittemore SR, Persson H, Hoffer B, Olson L (1988) Developmental appearance of nerve growth factor in the rat brain: significant deficits in the aged forebrain. Prog Brain Res 78: $27-31$.

Lindefors N, Ernfors P, Falkenberg T, Persson H (1992) Septal cholinergic afferents regulate expression of brain-derived neurotrophic factor and $\beta$-nerve growth factor mRNA in rat hippocampus. Exp Brain Res 88:78-90.

Loy R, Heyer D, Clagett-Dame M, DiStefano PS (1990) Localization of NGF receptors in normal and Alzheimer's basal forebrain with monoclonal antibodies against the truncated form of the receptor. $\mathbf{J}$ Neurosci Res 27:651-664.

McKhann G, Drachman DA, Folstein M, Katzman R, Price D, Stadlan EM (1984) Clinical diagnosis of Alzheimer's disease: report of the NINCDS-ADRDA Work Group under the auspices of Department of Health and Human Services Task Force on Alzheimer's Disease. Neurology 34:939-944.

Mesulam M, Mufson EJ, Levey AI, Wainer B (1983) Cholinergic innervation of cortex by the basal forebrain: cytochemistry and cortical connections of the septal area, diagonal band nuclei, nucleus basalis (substantia innominata), and hypothalamus in the rhesus monkey. $\mathrm{J}$ Comp Neurol 214:170-197.

Miller FD, Speelman A, Mathew TC, Fabian J, Chang E, Pozniak C, Toma JG (1994) Nerve growth factor derived from terminals selectively increases the ratio of $\mathrm{p} 75$ to trkA NGF receptors on mature sympathetic neurons. Dev Biol 161:206-217.

Mirra SS, Hart MN, Terry RD (1993) Making the diagnosis of Alzheimer's disease. Arch Pathol 117:132-144.

Mufson EJ, Kordower JH (1992) Cortical neurons express nerve growth factor receptors in advanced age and Alzheimer disease. Proc Natl Acad Sci USA 89:569-573.

Mufson EJ, Bothwell M, Kordower JH (1989a) Loss of nerve growth factor receptor-containing neurons in Alzheimer's disease: a quanti- 
tative analysis across subregions of basal forebrain. Exp Neurol 105: $221-232$.

Mufson EJ, Bothwell MA, Hersh LB, Kordower JH (1989b) Nerve growth factor receptor immunoreactive profiles in the normal aged human basal forebrain: colocalization with cholinergic neurons. J Comp Neurol 285:196-21\%.

Mufson EJ, Conner JM, Varon S, Kordower JH (1994) Nerve growth factor-like immunoreactive profiles in the primate basal forebrain and hippocampal formation. J Comp Neurol 341:507-518.

Mufson EJ, Connor JM, Kordower JH (1995) Nerve growth factor in Alzheimer's disease: defective retrograde transport to nucleus basalis. Neuroreport 6: in press.

Murase K, Nabeshima T, Robitaille Y, Quirion R, Ogawa M, Hayashi $\mathrm{K}$ (1993) NGF level is not decreased in the serum, brain-spinal fluid, hippocampus, or parietal cortex of individuals with Alzheimer's disease. Biochem Biophys Res Commun 193:198-203.

Olson L, Nordberg A, Von Holst H, Bäckman L, Ebcndal T, Alafuzoff I, Amberla K, Hartvig P, Herlitz A, Lilja A, Lundqvist H, Långström B, Meyerson B, Persson A, Viitanen M, Winblad B, Seiger $\AA$ (1992) Nerve growth factor affects ${ }^{11} \mathrm{C}$-nicotine binding, blood flow, EEG, and verbal episodic memory in an Alzheimer patient (case report). $\mathbf{J}$ Neural Trans Park Disease Dementia Section 4:79-95.

Phelps CH, Gage FH, Growdon JH, Hefti F, Harbaugh R, Johnston MV, Khachaturian ZS, Mobley WC, Price DL, Raskind M, Simpkins J, Thal LJ, Woodcock J (1989) Potential use of nerve growth factor in Alzheimer's disease. Neurobiol Aging 10:205-207.

Phillips HS, Hains JM, Armanani M, Laramee GR, Johnson SA, Winslow JW (1991) BDNF mRNA is decreased in the hippocampus in individuals with Alzheimer's disease. Neuron 7:695-702.

Saffran BN (1992) Should intracerebroventricular nerve growth factor be used to treat Alzheimer's disease. Perspect Biol Med 35:471-486

Saffran BN, Woo JE, Mobley WC, Crutcher KA (1989) Intraventricular NGF infusion in the mature rat brain enhances sympathetic innervation of cercbrovascular targets but fails to clicit sympathetic ingrowth. Brain Res 492:245-254.
Scott SA, Crutcher KA (1994) Nerve growth factor and Alzheimer's disease. Rev Neurosci 5:179-211.

Scott SA, Weingartner JA, Liang S, Crutcher KA (1994) Increased NGF-like activity in young but not aged rat hippocampus after septal lesions. Neurobiol Aging 15:337-346.

Sobreviela T, Clary DO, Reichardt LF, Brandabur MM, Kordower JH, Mufson EJ (1994) TrkA-immunoreactive profiles in the central nervous system: colocalization with neurons containing p75 nerve growth factor receptor, choline acetyltransferase, and serotonin. $J$ Comp Neurol 350:587-611.

Steininger TL, Wainer BH, Klein R, Barbacid M, Palfrey HC (1993) High affinity nerve growth factor receptor (trk) immunoreactivity is localized in cholinergic neruons of the basal forebrain and striatum of the rat. Brain Res 612:330-335.

Strada O, Hirsch EC, Javoy-Agid F, Lehéricy S, Ruberg M, Hauw J-J, Agid $Y$ (1992) Does loss of nerve growth factor receptors precede loss of cholinergic neurons in Alzheimer's disease? An autoradiographic study in the human striatum and basal forebrain. J Neurosci 12:4766-4774.

Weskamp G, Otten U (1987) Enzyme-linked immunoassay for nerve growth factor (NGF): a tool for studying regulatory mechanisms involved in NGF production in brain and in peripheral tissues. $J$ Neurochem 48:1779-1786.

Weskamp G, Gasser UE, Dravid AR, Otten U (1986a) Fimbria-fornix lesion increases nerve growth factor content in adult rat septum and hippocampus. Neurosci Lett 70:121-126.

Weskamp G, Lorez HP, Keller HH, Otten U (1986b) Cholinergic but not monaminergic denervation increases nerve growth factor content in the adult rat hippocampus and cerebral cortex. Arch Pharmacol 334:346-351.

Whittemore SR, Ebendal T, Larkfors L, Olson L, Seiger A, Stromberg I, Persson H (1986) Developmental and regional expression of $\beta$ nerve growth factor messenger RN $\Lambda$ and protein in the rat central nervous system. Proc Natl Acad Sci USA 83:817-821. 